\title{
AUTOMATED SEISMOGRAM ANALYSIS FOR THE TRIPARTITE BUG ARRAY: AN INTRODUCTION
}

\author{
MANFRED JoswiG* \\ Institut für Geophysik, Ruhr-Universität Bochum, Postfach 102148, D-4630 Bochum 1, Germany
}

\begin{abstract}
The tasks for automated epicenter determination in the Bochum University Germany (BUG) small array are subdivided for different signal-processing modules that utilize knowledge-based approaches. The modules are designed for complementary advantages to yield best system performance in an interdependent architecture. This "bottom-up" solution proceeds from reliable waveform parameters to more simple interpretation rules than in seismic expert systems that must cope with traditional detectors as erratic front ends.
\end{abstract}

Key Words: Automated bulletin, Event detection, Master event correlation, S-phase picker.

The three papers by Joswig (1993), Schulte-Theis and Joswig (1993), and Klumpen and Joswig (1993) describe different signal processing modules intended for the automated evaluation of seismograms. All approaches were developed within one research project with the final aim to produce an automated bulletin for the local seismicity monitored by the Bochum University Germany (BUG). The modules utilize explicit knowledge about the specific seismic situation and are designed as an interdependent system.

The BUG seismic network consists of a tripartite small array with the additional spare trace NA at the hub (see Fig. 1). It is complemented by a broad-band, three-component station of the German Regional Network (GRN) at the best array site KLB and two separate short-period, three-component stations $40 \mathrm{~km}$ west and east of Bochum installed some $100 \mathrm{~m}$ below surface in two coal mines (Joswig, 1987). The main purpose of the BUG network is to monitor the mining induced seismicity of the Ruhr Basin in NW Germany (Böhmer and others, 1989; Gibowitz, Harjes, and Schäfer, 1990).

In our investigations, all the efforts for automatization are focused on the small array. Its concept is so attractive because it promises similar quality of seismic monitoring as traditional, many station networks by significantly lower efforts in equipment, money, and staff (Joswig, 1992). The aperture of the BUG small array was selected for maximum resolution capabilities sacrificing to other criteria such as the lowest possible $\mathrm{S} / \mathrm{N}$ ratio or homogeneous site conditions. Its limitation to campus ground was favored to avoid any legal restrictions for public data communications. Without being charged for leased lines, we can permanently run the array with minimum

*Present address: Lehrstuhl für Meßtechnik, RWTH, Templer Graben 55, D-5100 Aachen, Germany. possible efforts for funding. As a result, however, the seismic noise varies significantly between the sites, even the optimum array beam is worse than the best single station KLB. To reach best detection results, we do not follow the usual ways of array analysis by beam-forming, $\mathrm{f}-\mathrm{k}$ analysis of vespagram calculation (see, e.g. Ringdal and Husebye, 1982) but rely on single-trace detections and voting.

Our scheme of automated seismogram processing is given in Figure 2: it starts by the sonogram-detector that can recognize the most usual, a priori known event types such as different local earthquakes, explosions, sonic bangs, and near-site traffic bursts. This identification by type is more detailed than the conventional report of onset times, so the subsequent coincidence evaluation should not just count on voting. Instead, some explicit rules can be defined for COASSEIN that yield an improved reliability of the array-wide type identification and exclude all false alarms.

The consequent refinement of the type-based event classification is performed by Dynamic Waveform Matching (DWM) acting on a set of master events. The spatial resolution can be improved on an order of magnitude and even resolves time clustering of event sequences. On the other hand, this approach more crucially depends on a priori known seismograms than the sonogram-detection does. To overcome this restriction for the automated bulletin, we had to realize a second processing path that does not depend on master events. Instead, it calculates the array azimuth by a monlinear cross-correlation of single traces - also by DWM-and determines the actual $t_{\mathrm{S}}-t_{\mathrm{P}}$ time by a new three-component phase picker. This approach utilizes polarization images to recognize the complex signature of high-frequency particle motion. Similar to the sonogram-detector, it follows the theory of mental images to copy some behavior of the human cognition process (Joswig, $1990,1991)$. 


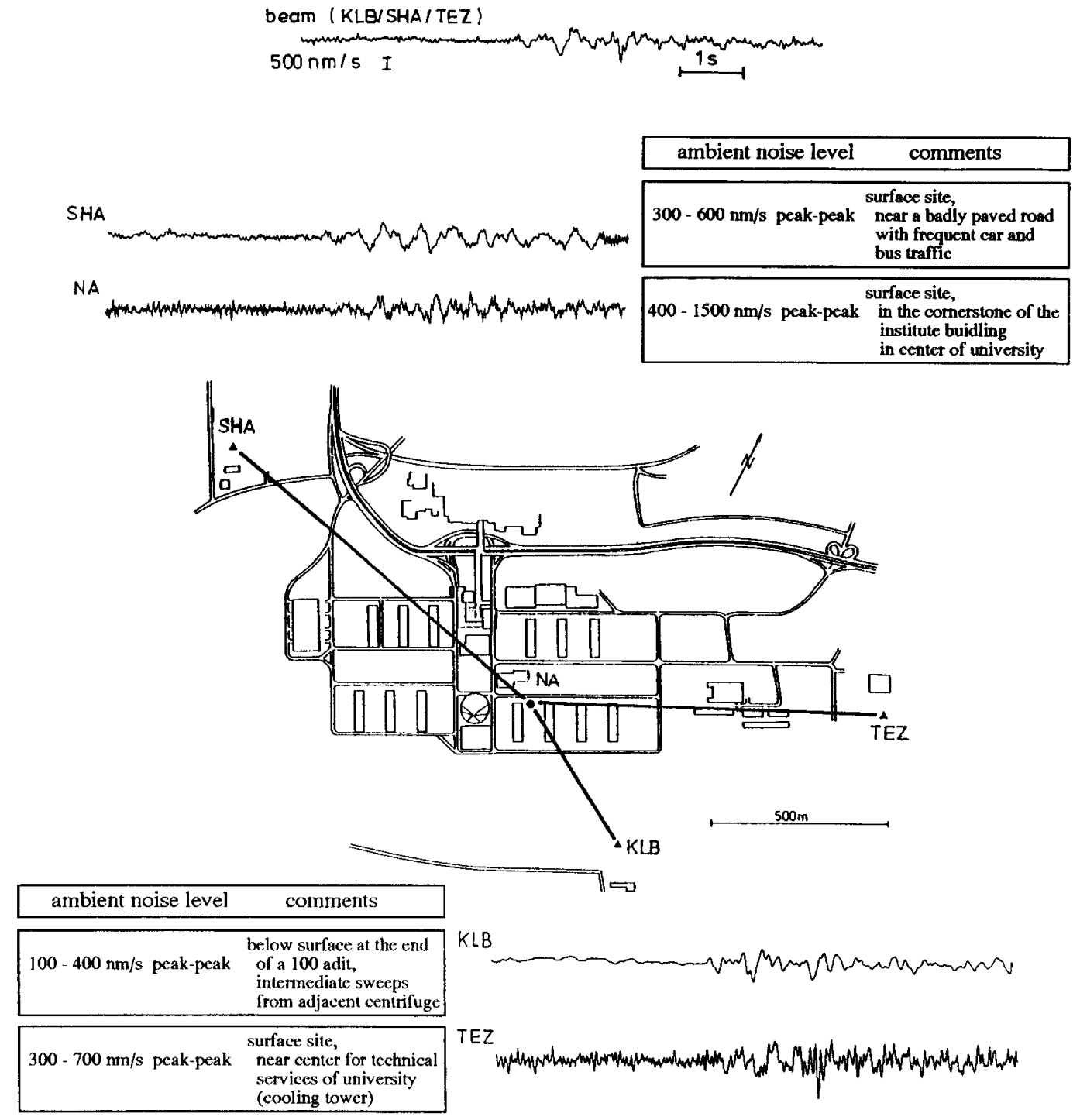

Figure 1. Site map and station characteristics of BUG small array: $8 \mathrm{sec}$ seismograms show noise prerun and P-phase of a local event in $40 \mathrm{~km}$ distance. Even optimum array beam has worse $\mathrm{S} / \mathrm{N}$ ratio than best single station KLB.

An automated bulletin is useful only if all modules perform well even in decreased $\mathrm{S} / \mathrm{N}$ ratio because weak events make up the vast majority of any observatory routine work. For the design of DWM and three-component analysis, this condition meant to utilize the event parameters that have been derived already by SONODET/COASSEIN. Instead of self-contained programs, we got interdependent approaches with characteristics that are complementary in many aspects:

(Ia) The sonogram-detection is based on some few, simply derived seismograms acting as reference. It handles all incoming data and yields robust but necessarily fuzzy results.

(Ib) DWM on master events is able to resolve fine structure details of a few $100 \mathrm{~m}$ even at a distance of $40 \mathrm{~km}$. However, it demands a carefully selected set of appropriate master events which is an order of magnitude larger than the number of sonogram-patterns (for the "Hamm" rockbursts: 1 sonogram-pattern vs 12 master events; for "Velbert" quarry blasts: 1-22). Its application is restricted to a subset of events preselected by the sonogramdetector.

(IIa) DWM for correlation of array traces does not depend on master events but improves the relative onset times to one sample (!) uncertainty. It is based on the sonogram type identification to adjust the initial path in the variety of correlation maxima determined for weak events. Although the whole path is known in detail after DWM has succeeded, 


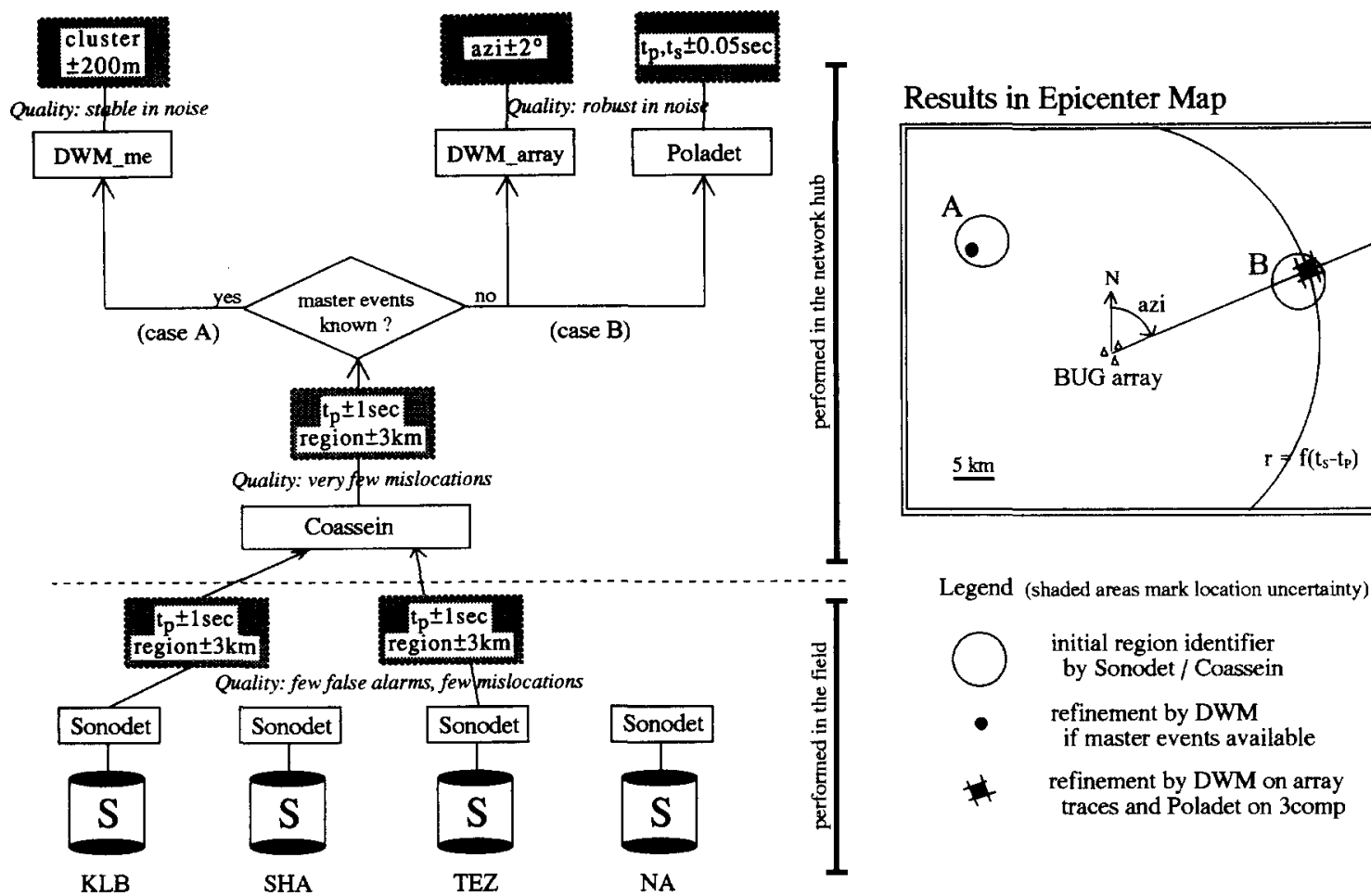

Figure 2. Modules for automated seismogram analysis in BUG small array: aim of epicenter determination is reached by two paths-(A) if a master event can be located, DWM yields relative deviation (B) else array azimuth and distance by $t_{\mathrm{S}}-t_{\mathrm{P}}$ will refine initial type identification of sonogram-detector and coincidence evaluation.

its absolute uncertainty for phase onsets remains at $1 \mathrm{sec}$ as already given by the resolution of SONODET.

(IIb) The three-component phase picking yields onset times of $\pm 50 \mathrm{msec}$ accuracy but its inherent azimuth determination is uncertain within one quadrant. Even more, to achieve good results for weak events, the direction should be known for best $\mathrm{P} / \mathrm{SV} / \mathrm{SH}$ decomposition. Although it performs well in noise, its robustness is beaten by DWM with master events.

Altogether, the different approaches fit into the scheme of Figure 2 where subsequent steps refine the given knowledge but also depend on these a priori "hints" for acceptable performance on routine data. By this concept, we obtained human-like performance for data sets that contain 1-4 years' complete waveform catalogs of the BUG array.

The described system for automated seismogram analysis starts "bottom up" from the raw data. It derives the standard event parameters $\left(t_{\mathrm{p}}, t_{\mathrm{S}}\right.$, azimuth, cluster affiliation) for further analysis as reliable as possible. The alternative in designing knowledgebased approaches is "top down" (Chiaruttini, Roberto, and Saitta, 1989; Bache and others, 1990). There one tries to code as much explicit knowledge in rules, descriptions, and heuristics as possible. We initially went this way too but learned we were caught in the handling of ever complicated exceptions while forgetting about the routine tasks. There the rules are simple but waveform analysis is difficult. Going "bottom up" now, our system is able to process the majority of routine events but naturally will give up on complicated exceptions. However, if this situation is handled by "graceful degradation" where the system itself can report for its incompetence, all the other results should be reliable enough to relieve humans on the greater part of observatory routine works.

Acknowledgments - This work was supported by Deutsche Forschungsgemeinschaft under grant $\mathrm{Ha} 842 / 8-1$.

\section{REFERENCES}

Bache, T. C., Bratt, S. R., Wang, J., Fung, R. M., Kobryn, C., and Given, J. W., 1990, The intelligent monitoring system: Bull Seism. Soc. America, v. 80, no. 6, pt. B, p. 1833-1851.

Böhmèr, M., Harjes, H.-P., Weber, V., and Will, M., 1989 , Seismologische Untersuchungen von Erderschütterungen im Ruhrgebiet: Das Markscheidewesen, v. 92, no. 2, p. $210-226$.

Chiaruttini, C., Roberto, V., and Saitta, F., 1989, Artificial intelligence techniques in seismic signal interpretation: Geophys. Jour. I. v. 98, no. 2, p. 223-232.

Gibowicz, S. J., Harjes, H.-P., and Schäfer, M., 1990 , Source parameters of seismic events at Heinrich Robert mine, Ruhr Basin, Federal Republik of Germany: 
evidence for non-double-couple events: Bull. Seism. Soc. America v. 80, no. 1, p. 88-109.

Joswig, M., 1987, Methoden zur automatischen Erfassung und Auswertung von Erdbeben Seismischen Netzen und ihre Realisierung beim Aufbau des lokalen "BOCHUM UNIVERSITY GERMANY"-Netzes: Wissenschaftl. Veröffentl. (Reihe A), Inst. Geophysik, Ruhr-Univ., Bochum, p. 1-124.

Joswig, M., 1990, Wissensbasierte Erdbebenerkennung mit Sonogrammen als mentalen Bilder, in Marburger, $\mathrm{H}$., ed., GWAI-90: Springer-Verlag, IFB 251, Berlin, p. $144-149$.

Joswig, M., 1992, System architecture of seismic networks and its implications to network automatization, in Camelbeeck, T., Flick, J., and Ducarme, B., eds., Local and national seismic networks: on-line data processing with microcomputer facilities: Cahiers du Centre Europeen de Geodynamique et de Seismologie, v. 5, Luxembourg, p. 75-84.

Joswig. M., 1991, Automated detection and interpretation of earthquake seismograms by adaptive pattern recognition, in Krönig, D., and Lang, M. eds., Physik und Informatik--Informatik und Physik, SpringerVerlag, IFB 306, Berlin, p. 153-161.

Joswig, M., 1993, Single-trace detection and array-wide coincidence association of local earthquakes and explosions: Computers \& Geosciences, v. 19, no. 2, p. $207-221$

Klumpen E., and Joswig, M., 1993, Automated reevaluation of local earthquake data by application of generic polarization patterns for $\mathbf{P}$ - and S-onsets: Computers \& Geosciences, v. 19 , no. 2 , p. $223-231$.

Ringdal, F., and Husebye, 1982, Application of arrays in the detection, location, and identification of seismic events: Bull. Seism. Soc. America, v. 72, no. 6, pt. B, S201-S224.

Schulte-Theis, H., and Joswig, M., 1993, Clustering and location of mining induced seismicity in the Ruhr basin by automated master event comparison based on Dynamic Waveform Matching (DWM): Computers \& Geosciences, v. 19, no. 2, p. 233-241. 